\section{STRENGTH ANALYSIS OF PIN CONNECTIONS USING COMPUTER AIDED SYSTEMS}

PETR BERNARDIN, VACLAVA LASOVA, FRANTISEK SEDLACEK

University of West Bohemia in Pilsen

RTI - Regional Technological Institute

Pilsen, Czech Republic

DOI: 10.17973/MMSJ.2017_03_2016103

e-mail: berny@kks.zcu.cz

The aim of this work was to analyse the options for predicting pin connections, using modern computer aided systems. These advanced methods include Special-Purpose Programs and Finite Element Analysis, which fundamentally differ in their duration and precision of results. Some of these methods allow calculation including the influence of the force and pin position, position of the stiffness centre, and stiffness of the connected parts. These conditions significantly affect the results. The evaluation of results is different in all the calculation methods. The resulting evaluation in Finite Element Analysis is a task for the designer, as well as the calculation using some Special-Purpose Programs (for example BSPOJ). Other Special-Purpose Programs (for example KISSsoft or MITCalc) evaluate the pin connection automatically. This work describes the comparison of these prediction methods for pin connections, and the evaluation of the results.

KEYWORDS

pin, connection, finite element analysis, strength check, permissible stress

\section{Introduction}

Pin connections are one of the basic methods for connecting parts. The great advantage of this connection is that it is removable but notches are created in the connected parts in the manufacturing of this coupling This results in local stress concentration and a decrease of the strength of such joints. Because of the widespread usage of pin couplings, the emphasis is given to accurate prediction of their properties, especially strength. There are several options for predicting pin connections, such as analytical calculations, Special-Purpose Programs (SPPs), or Finite Element Analysis (FEA). Nowadays companies do not usually have all these prediction methods available. The main reason is price and the maintenance of the software. In particular, smaller companies are usually equipped with SPPs [MITCalc 2003-2013, KISSsoft AG 1998-2014, BSPOJ 1992] based on spreadsheets or databases, because FEA is less affordable and is a time consuming process. Consequently, they have no other choice but to accept the information and values obtained from these SPPs, even without understanding their principles. This scientific work describes the comparison of the prediction methods of the pin connections so that the results should be usable for designers in the evaluation of similar connections. One section of this paper is devoted to comparing the programs with respect to material parameters, types of loading, evaluation criterions and results. A detailed comparison was undertaken for a specific connection using securing pins between two steel boards. This work is a continuation of the scientific work [Lasova 2015], where the capabilities of FE method and SPPs in evaluation of gears were compared.

\begin{tabular}{|c|c|c|c|}
\hline Parameters & Quantity & Value & Units \\
\hline Functional length of pin & $\mathrm{L}$ & 70 & {$[\mathrm{~mm}]$} \\
\hline Diameter of pin & $\mathrm{d}$ & 30 & {$[\mathrm{~mm}]$} \\
\hline Contact length pin-bottom board & $\mathrm{s}_{1}$ & 35 & {$[\mathrm{~mm}]$} \\
\hline Contact length pin-top board & $\mathrm{s}_{2}$ & 35 & {$[\mathrm{~mm}]$} \\
\hline Thickness of top board & $\mathrm{t}_{1}$ & 100 & {$[\mathrm{~mm}]$} \\
\hline Thickness of bottom board & $\mathrm{t}_{2}$ & 70 & {$[\mathrm{~mm}]$} \\
\hline
\end{tabular}

Table 1. Dimensions of the pin connection

\section{Shape and material selection}

For the purpose of comparing the prediction methods, a pin connection was designed. The shape of the connected parts is based on an existing design used for locking a tailstock on a lathe bed [Marek 2015]. The shape of the connected parts, pins positions (marked red and numbered $1-8$ ) and the way of loading are shown in Figure 1. The pin connection was loaded by force $F$. $160 \mathrm{kN}$. The connected parts were fixed in the pin axis direction by other parts of assembly.

Two boards were made of steel in accordance with CSN 11500. Dimensions of the pin and both boards are shown in Tab. 1
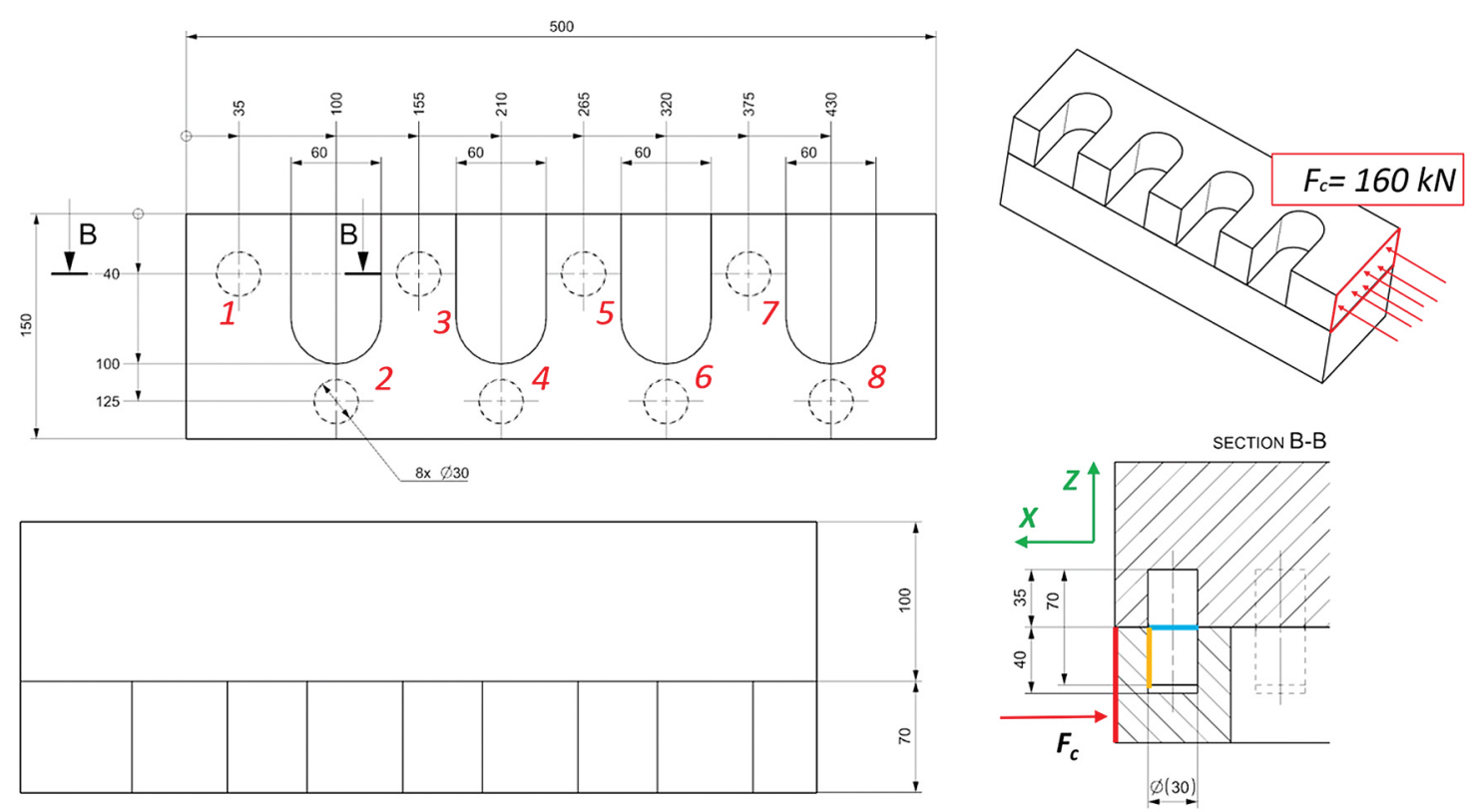

Figure 1. The pin connection 


\section{Prediction and evaluation of the pin connection}

\subsection{BSPOJ software}

The BSPOJ is Skoda Machine Tool, a.s. company software, and was provided for scientific purposes. The BSPOJ calculation includes the influence of the stiffness centre location (caused by the pin position). It does not include the influence of the stiffness of the connected parts (i.e., it calculates with their infinity stiffness). From the stiffness centre location, the software allows the most loaded pin to be found and calculates comparative shear and contact stress. The force applied to the most loaded pin, comparative shear stress and comparative contact pressure belonging to the designed pin connection are shown in equations (1) (3). The corresponds to uniform force distribution, with a value of $20 \mathrm{kN}$ per one pin. The similarity is caused by infinity stiffness of the connected parts.

$$
\begin{array}{r}
F_{\text {pin }}=20029 \mathrm{~N} \\
p_{1}=\frac{F_{\text {pin }}}{d \cdot s_{1}}=19.1 \mathrm{MPa} \\
\tau_{S}=\frac{F_{\text {pin }}}{\frac{\pi \cdot d^{2}}{4}}=28.3 \mathrm{MPa}
\end{array}
$$

The evaluation of the safety factors (shear, contact pressure) are not included in the BSPOJ software and its choice is a task for a designer.

\subsection{MITCalc software}

The calculation using the MITCalc software includes the evaluation of the shear stress and contact pressure of the pin. For a connection with more pins, the non-uniform load distribution among the pins can be detected. The actual connection area can be lower than the theoretically set area and the ratio between these areas is defined by the coefficient of load distribution $\mathrm{K}_{\mathrm{L}}$. This coefficient is included in MITCalc software and is used in equations (4) and (5). This coefficient includes the nonuniform load distribution caused by imperfect manufacturing process and by assembly inaccuracies. The non-uniform load distribution caused by different stiffnesses of the connected parts, by the stiffness centre location, or by the position of the load is not included. For the purpose of pin connection calculation the MITCalc software requires the reduction parameters to be selected. These parameters reduce the load capacity of the pin connection, namely the service factors $K_{S p}$ (pressure), $K_{S b}$ (bending, shear) and load distribution factor $K_{L}$. The previously mentioned parameters were set according to the designed pin connection (see Tab. 2). Eight pins are used in the connection and the value 0.5 was chosen for the load distribution factor $K_{L}$. The values of the coefficients as well as the values of permissible stresses were chosen by MITCalc according to the ultimate tensile strength, type of fit, type of pin, type of loading and number of pins. The permissible stresses are calculated based on the internal factors. These unique parameters are recommended by the MITCalc software.

\begin{tabular}{|c|c|c|c|}
\hline Parameters & Quantity & Values & Units \\
\hline Type of loading & \multicolumn{3}{|c|}{ Static load } \\
\hline Type of pin & \multicolumn{4}{|c|}{ Fixed pin ISO 2338 A } \\
\hline Type of fit & \multicolumn{3}{|c|}{ Fixed fit } \\
\hline Desired safety & $\mathrm{s}_{\mathrm{f}}$ & 1.70 & {$[-]$} \\
\hline Load distribution factor & $\mathrm{K}_{\mathrm{L}}$ & 0.50 & {$[-]$} \\
\hline Service factor (pressure and bending, shearing) & $\mathrm{K}_{\mathrm{Sp}}, \mathrm{K}_{\mathrm{Sb}}$ & 1.00 & {$[-]$} \\
\hline
\end{tabular}

Table 2. Reduction factors, operational and mounting parameters of the coupling according to the MITCalc software

Mechanical parameters of the pin and connected parts are described in Tab. 3.

\begin{tabular}{|c|c|c|c|c|}
\hline Parameters & Quantity & Pin & $\begin{array}{c}\text { Connected } \\
\text { parts }\end{array}$ & Units \\
\hline Material & $\begin{array}{c}\text { Surface } \\
\text { hardened steel } \\
(45-53 \mathrm{HRC})\end{array}$ & CSN 11500 & \\
\hline Ultimate tensile strength & $R_{\text {mmin }}$ & 650 & 500 & {$[\mathrm{MPa}]$} \\
\hline Permissible pressure (fixed fit) & $p_{D}$ & 220 & 125 & {$[\mathrm{MPa}]$} \\
\hline Permissible shear stress & $\tau_{D}$ & 100 & - & {$[\mathrm{MPa}]$} \\
\hline Permissible bending stress & $\sigma_{D}$ & 160 & - & {$[\mathrm{MPa}]$} \\
\hline
\end{tabular}

Table 3. The material of pin and both connected boards according to the MITCalc software

The pin strength check for shearing according to the MITCalc software is shown in equation (4).

$$
K_{S}=\frac{\tau_{D}}{\tau_{S}}=\frac{\tau_{D}}{K_{S b} \frac{4 \cdot F_{C}}{\pi \cdot d^{2} \cdot i \cdot K_{I}}}=\frac{100}{56.6}=1.77
$$

The pin count is described by the $i$ parameter, which was used in equations (4) - (7). The pin-board strength check of contact pressure based on MITCalc software shows equation (5).

$$
K_{o t l}=\frac{p_{D}}{p_{1}}=\frac{p_{D}}{K_{S p} \frac{F_{c}}{d \cdot s_{1} \cdot i \cdot K_{L}}}=\frac{125}{38.1}=3.28
$$

The resulting values of the safety factors are summarized in Tab. 4.

\begin{tabular}{|c|c|c|c|}
\hline Parameters & Quantity & Values & Units \\
\hline Shearing safety & $\mathrm{K}_{\mathrm{s}}$ & 1.77 & {$[-]$} \\
\hline Contact pressure safety & $\mathrm{K}_{\mathrm{otl}}$ & 3.28 & {$[-]$} \\
\hline
\end{tabular}

Table 4. The resulting safety factors (shearing, contact pressure) based on MITCalc software

\subsection{KISSsoft software}

KISSsoft (as well as MITCalc) software allows the inclusion of the non-uniform load distribution caused by assembly inaccuracies and manufacturing. The non-uniform load distribution caused by different stiffnesses of the connected parts, by the stiffness centre location, or by the load position is not included. The KISSsoft software does not contain a module for calculating the connection with pins in a planar arrangement. It contains only the shaft connection calculations, namely the cross pin under torque, longitudinal pin under torque, guide pin under bending, bolt under shearing action (double shear), and bolts in circular arrangement (single shear). This last method can be utilized for the designed coupling, but the torque must be specified so that the pin loading corresponds to loading of the planar arranged pin coupling. The loading per one pin was set according to BSPOJ and MITCalc loading $-20 \mathrm{kN}$. The material was set according to the task

\begin{tabular}{|c|c|c|c|c|}
\hline Parameters & Quantity & Pin & $\begin{array}{c}\text { Connected } \\
\text { parts }\end{array}$ & Units \\
\hline Material & & $\begin{array}{c}\text { Surface } \\
\text { hardened steel } \\
(45-53 \mathrm{HRC})\end{array}$ & CSN 11500 & \\
\hline Ultimate tensile strength & $R_{\text {mmin }}$ & 650 & 500 & {$[\mathrm{MPa}]$} \\
\hline Permissible pressure (fixed fit) & $p_{D}$ & - & 175 & {$[\mathrm{MPa}]$} \\
\hline Permissible shear stress & $\tau_{D}$ & 130 & - & {$[\mathrm{MPa}]$} \\
\hline
\end{tabular}

Table 5. The material parameters of the pin and both connected boards according to the KISSsoft software

assignment. The values of permissible stresses based on the KISSsoft software are shown in Tab. 5 . 
The permissible stresses (KISSsoft) based on the ultimate tensile strength and reduction coefficients may vary in comparison with other SPPs, which was explained in the Discussion chapter. These values are recommended by KISSsoft software developer. This influences the resulting values of the safety factors. These safety factors (pressure, shearing) according to the KISSsoft software are described in equations (6) and (7).

$$
\begin{gathered}
K_{s}=\frac{\tau_{D}}{\tau_{S}}=\frac{\tau_{D} \cdot c_{d}}{K_{A} \frac{4 \cdot F_{c}}{\pi \cdot d^{2} \cdot i}}=\frac{130}{35.6}=3.67 \\
K_{\text {otl }}=\frac{p_{D}}{p_{1}}=\frac{p_{D} \cdot c_{d}}{K_{A} \frac{F_{c}}{d \cdot s_{1} \cdot i}}=\frac{175}{23.8}=7.35
\end{gathered}
$$

The service factor $K_{A}$ (KISSsoft software) is analogous with coefficients $K_{S p^{\prime}} K_{S b}$ (MITCalc software), however the value is not equal (1.25). The values of the required safety are also different as well as the resulting safety factors of the coupling. The KISSsoft calculation also includes dynamic coefficient $c_{d}$, whose value depends on the type of loading (Static, repeated, alternating). The coefficient $c_{d}$ is included in the service factors in the MITCalc calculation. The values valid for the designed pin coupling are shown in Tab. 6 and their choice depends on the working characteristic of the driving and driven part of the joint.

\begin{tabular}{|c|c|c|c|}
\hline Parameters & Quantity & Values & Units \\
\hline Service factor & $\mathrm{K}_{\mathrm{A}}$ & 1.25 & {$[-]$} \\
\hline Desired safety & $\mathrm{s}_{\mathrm{f}}$ & 1.00 & {$[-]$} \\
\hline Dynamic factor & $\mathrm{c}_{\mathrm{d}}$ & 1.00 & {$[-]$} \\
\hline
\end{tabular}

Table 6. The reduction factors and the desired safety factor based on KISSsoft software

The resulting values of the safety factor for shearing and contact pressure are summarized in Tab. 7.

\begin{tabular}{|c|c|c|c|}
\hline Parameters & Quantity & Values & Units \\
\hline Shearing safety & $\mathrm{K}_{\mathrm{s}}$ & 3,67 & {$[-]$} \\
\hline Contact pressure safety & $\mathrm{K}_{\text {ofl }}$ & 7,35 & {$[-]$} \\
\hline
\end{tabular}

Table 7. The resulting safety factors (shearing, contact pressure) obtained by KISSsoft

\subsection{FEA}

The FEA was performed using the Siemens NX software with the NX NASTRAN solver. The FEA was used to determine the distribution of the forces and stresses in the designed pin connection. The determination of the required results was performed using the Linear Statics analysis (LSA) and for refining the results the Non-linear multi-step (NLA) analysis. The useful results obtained by all the methods were compared.

The 3D model was meshed according to generally known principles [Lasova 2015], see Fig. 2. All parts were meshed using CTETRA(10) elements for solving the LSA, and the contact surfaces of the pin

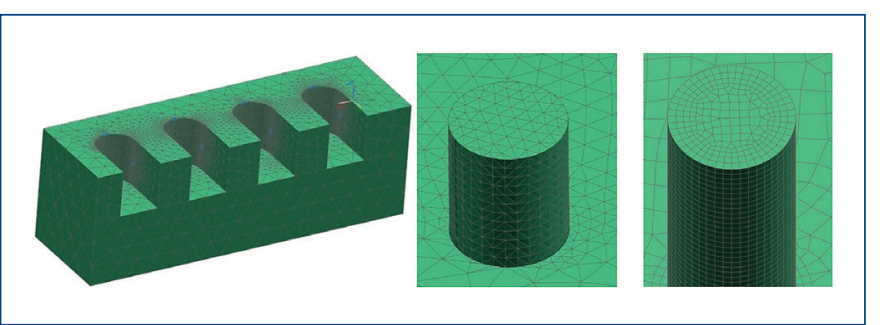

Figure 2. 3D meshed model using the Linear Statics (left and middle) and Non-linear Multi-Step analysis (right) were first covered with a finer 2D mesh. All parts were finer meshed using Linear Hexahedron elements for solving the NLA. The boundary conditions were applied in accordance with the load in Fig. 1, the bottom board was fully fixed and the upper board was fixed in the pin axis direction. The pins and the bottom board were coupled using shared nodes, the surface-to-surface contact was set between the pins and the upper board. These boundary conditions are valid for both types of analyses (LSA and NLA) as well as the load distribution to particular pins. The values obtained by the NLA and LSA do not differ more than $2 \%$, therefore the LSA results were used, see Tab. 8 . The FEA calculation took one hour for the LSA and two hours for the NLA.

\begin{tabular}{|c|c|c|}
\hline & Force per pin [kN] & \% of total pre-stressing force \\
\hline Pin 1 & 66.2 & 41.7 \\
\hline Pin 2 & 25.3 & 15.9 \\
\hline Pin 3 & 7.5 & 4.7 \\
\hline Pin 4 & 18.6 & 11.7 \\
\hline Pin 5 & 5.4 & 3.4 \\
\hline Pin 6 & 15.8 & 10.0 \\
\hline Pin 7 & 5.8 & 3.6 \\
\hline Pin 8 & 15.1 & 9.5 \\
\hline
\end{tabular}

Table 8. The load distribution per particular pins determined by LSA

The relationship between the pin-board contact pressure and the $Z$ direction as well as the shear stress inside the most loaded pin (Pin 1) are shown in Fig. 3. The results obtained by LSA are marked by red dotted line and results obtained by NLA are marked by blue dotted line.

These relationships are based on the boundary conditions described in Fig. 1. The contact pressure was tracked at the orange edge, the shear stress was tracked at the section of the pin marked by blue line (see B-B Section in Fig. 1). The results are influenced by the node singularities on the sharp edges (see the I. and II. areas in Fig. 3).

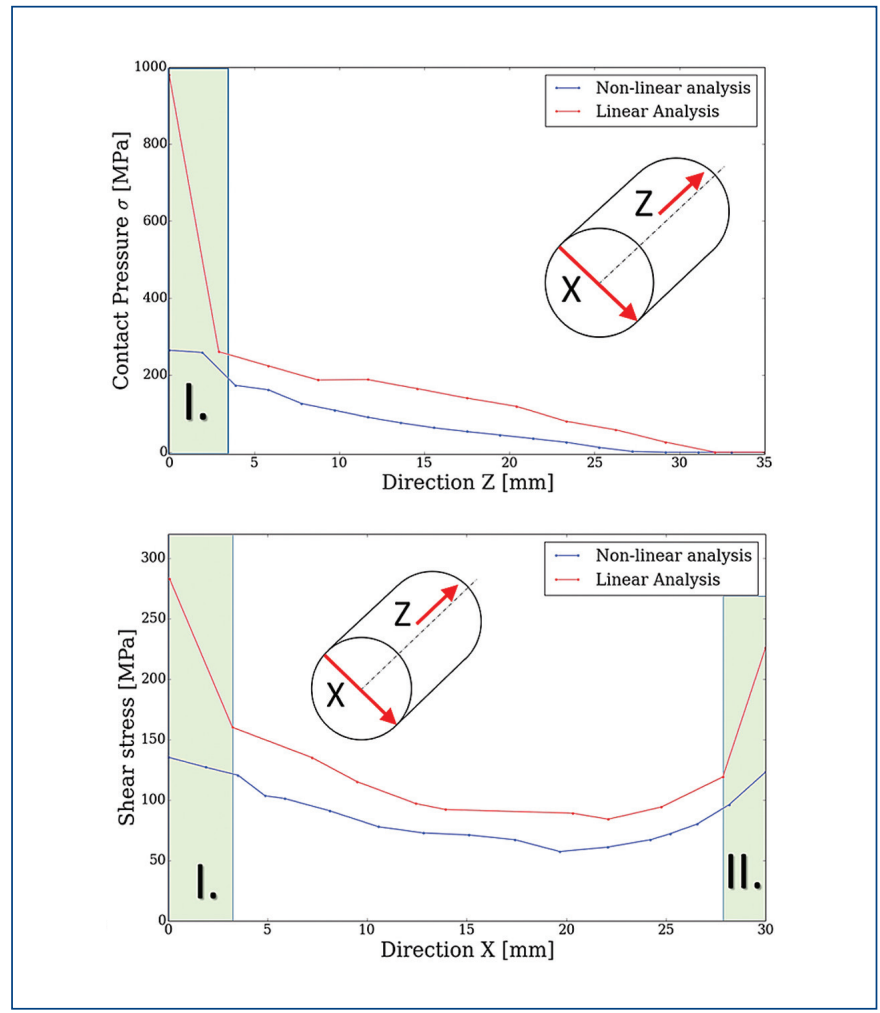

Figure 3. Contact pressure (upper $-Z$ direction)

and Von-Mises stress (lower $-X$ direction) per most loaded pin 
The node singularities lead to the local stress peaks and depend on the element size. Smaller influence of the node singularities was found by the NLA (in comparison with the LSA). The difference between both stresses outside the I. and II. area was caused by the influence of material nonlinearity included in NLA, which is not included in LSA These relationships are not fully comparable with the contact pressure gained by the SPPs, which are related to the surface, but not to the edge. The stress values $\tau_{s}$ and $p_{1}$ (see Tab. 9) were determined using the FEA (LSA and NLA) and belong to the contact and shear surface between the pin and the board. These values were averaged for their comparability with the SPP stress values.

\begin{tabular}{|c|c|c|c|c|}
\hline \multirow{2}{*}{ Parameters } & \multirow{2}{*}{ Quantity } & \multicolumn{2}{|c|}{ FEA } & \multirow{2}{*}{ Units } \\
\cline { 2 - 5 } & $\begin{array}{c}\text { Linear Static } \\
(\text { LSA) }\end{array}$ & $\begin{array}{c}\text { Non-linear } \\
\text { (NLA) }\end{array}$ & \\
\hline Average shear stress & $\tau_{s}$ & 116.4 & 80.6 & {$[\mathrm{MPa}]$} \\
\hline Average contact pressure & $p_{1}$ & 71.9 & 51.3 & {$[\mathrm{MPa}]$} \\
\hline
\end{tabular}

Table 9. The average shear stress and contact pressure obtained by Linear and Non-linear Analysis

\section{Discussion}

The compared prediction methods differ depending on whether the calculation includes the influence of non-uniform load distribution (caused by position of load, stiffness centre position, different stiffness of the connected parts, imperfect manufacturing process and assembly inaccuracies) or not, as shown in Tab. 10.

It was found that the values of the desired safeties gained by particular prediction methods vary significantly, as well stress values, permissible stress values and reduction factors. The values of permissible stresses are different in each software even when using the same material (the same yield strength). The difference is caused by the different calculation method and different internal factors implemented in the SPP. These recommended values are based on experiences of the software developer. The resulting values of stress (pressure, shear) obtained using the SPPs and FEA are described in Tab. 11.

The resulting values of the safety factor for shearing and contact pressure obtained by MITCalc a KISSsoft software are summarized in Tab. 12

The SPPs are not able to determine the non-uniform load distribution caused by different stiffness of the connected parts and therefore all the pins used in the SPP calculation were loaded with approximately force $20 \mathrm{kN}$. The force acting to Pin 1 obtained by FEA reaches the value of $66.2 \mathrm{kN}$. This loading was used for the reliable comparison with all the SPPs, see Tab. 13. The service factor $K_{A}$ (KISSsoft) and load distribution factor $K_{L}$ (MITCalc) was set to 1 .

All results obtained by the SPPs are similar. The NLA results show that the mutual rotation of the connected parts causes the change of the shear stress tensor direction and the creation of parasitic loading. The NLA is less influenced by the node singularities than the LSA and include the area of plastic deformation. Therefore the value of the shear stress gained by NLA is lower than the values gained by SPPs. The NLA seems to be the appropriate tool for the contact pressure and shear stress determination. The only disadvantage of the NLA is a lack of safety evaluation. If a common user do not have the FEA available, the real loading acting the most loaded pin must be found alternatively. Calculation using the uniform load distribution may lead to wrong results (see Tab. 11).

\section{Conclusion}

The main goal of this work was to analyse and compare options for predicting pin connections, namely the SPPs and FEA. The designed pin coupling contained eight securing pins in a planar arrangement. None of the examined options allows the integration of all the conditions of a

\begin{tabular}{|c|c|c|c|c|c|}
\hline & $\begin{array}{c}\text { Pin location } \\
\text { influence }\end{array}$ & $\begin{array}{c}\text { Centre of } \\
\text { stiffness influence }\end{array}$ & $\begin{array}{c}\text { Reduction } \\
\text { factors }\end{array}$ & $\begin{array}{c}\text { Safety factors } \\
\text { (contact pressure/shearing) }\end{array}$ & $\begin{array}{c}\text { The influence of } \\
\text { the connected parts stiffness }\end{array}$ \\
\hline BSPOJ & YES & YES & NO & NO & NO \\
\hline MITCalc & NO & NO & YES & YES & NO \\
\hline KISSsoft & NO & NO & YES & YES & NO \\
\hline FEA & YES & YES & NO & NO & YES \\
\hline
\end{tabular}

Table 10. The compared prediction methods

\begin{tabular}{|c|c|c|c|c|c|c|c|}
\hline \multirow{2}{*}{ Parameters } & \multirow{2}{*}{ Quantity } & \multirow{2}{*}{ BSPOJ } & \multirow{2}{*}{ MITCalc } & \multirow{2}{*}{ KISSsoft } & \multicolumn{4}{|c|}{ FEA } \\
\cline { 6 - 9 } & & & & & Linear Static (LSA) & Non-linear (NLA) & Units \\
\hline Comparative shear stress & $\tau_{s}$ & 28.3 & 56.6 & 35.6 & 116.4 & 80.6 & {$[\mathrm{MPa}]$} \\
\hline Comparative contact pressure & $\mathrm{p}_{1}$ & 19.1 & 38.1 & 23.8 & 71.9 & 51.3 & {$[\mathrm{MPa}]$} \\
\hline
\end{tabular}

Table 11. The comparative shear stress and contact pressure based on prediction methods

\begin{tabular}{|c|c|c|c|c|}
\hline Parameters & Quantity & KISSsoft & MITCalc & Units \\
\hline Shearing safety & $\mathrm{K}_{\mathrm{s}}$ & 3.67 & 1.77 & {$[-]$} \\
\hline Contact pressure safety & $\mathrm{K}_{\mathrm{otl}}$ & 7.35 & 3.28 & {$[-]$} \\
\hline
\end{tabular}

Table 12. The resulting safety factors (shearing, contact pressure) obtained by MITCalc and KISSsoft

\begin{tabular}{|c|c|c|c|c|c|c|c|}
\hline \multirow{2}{*}{ Parameters } & \multirow{2}{*}{ Quantity } & BSPOJ & \multirow{2}{*}{ MITCalc } & \multirow{2}{*}{ KISSsoft } & \multicolumn{3}{|c|}{ FEA } \\
\cline { 5 - 8 } & & & & & Linear Static (LSA) & Non-linear (NLA) & Units \\
\hline Comparative shear stress & $\tau_{s}$ & 93.7 & 93.7 & 94.3 & 116.4 & 80.6 & {$[\mathrm{MPa}]$} \\
\hline Comparative contact pressure & $p_{1}$ & 63.2 & 63.1 & 63.0 & 71.9 & 51.3 & {$[\mathrm{MPa}]$} \\
\hline
\end{tabular}

Table 13. The comparative shear stress and contact pressure obtained by FEA and analytical equation 
designed pin coupling. Both FEA and BSPOJ include the influence of the pin location and the stiffness centre location. Moreover the FEA is the only option for determining the real load distribution caused by the stiffness of connected parts. The safety evaluation is available only in MITCalc and KISSsoft software. The KISSsoft software evaluates only the shaft connections loaded by torsion. Therefore it was necessary to modify the boundary conditions. The required force was applied by the torque and the lever arm. The MITCalc software includes the prediction method for the designed type of connection (planar arranged pins), includes the reducing factors and takes a relatively short time. To obtain the most accurate results, the best choice is the combination of the FEA results and the SPP results. The FEA is the only way to determine the force acting on most loaded pin. The SPP is the only option to automatically determine the safeties (shearing, contact pressure). It can be performed manually, but it poses high demands on the designer's experience and knowledge and can lead to errors. The only disadvantage of using the combination of the FEA and the SPP (MITCalc) is the increased funding required. The other option evaluates the Von-Mises stress inside a pin. This evaluation is based on the ultimate tensile strength and the safety requirements and it is not included in SPPs.

\section{Acknowledgements}

Authors of the work presented herein gratefully acknowledge the support in the form of the institutional funding for long-term strategic development of the University of West Bohemia provided by the Ministry of Education of the Czech Republic.

\section{References}

[BSPOJ 1992] BSPOJ, Skoda Machine Tool a.s., (company proprietary software), Pilsen, 1992.

[KISSsoft AG 1998-2014] KISSsoft $®$, Bubikon: Available from: www. KISSsoft.ch/english/downloads/, 1998-2014.

[Lasova 2011] Lasova, V. Method of finite elements in calculations of machine tools. Pilsen: University of West Bohemia, 2011. ISBN 978-80261-0008-9 (in Czech)

[Lasova 2015] Lasova, V. et al. Comparison of capabilities of finite element method and specialized software programs in evaluation of gears. MM (Modern Machinery) Science Journal, June 2015, 610-612, DOI: 10.17973/MMSJ.2015_06_201515

[Marek 2015] Marek, J. et al. Design of CNC Machine Tools. Prague: MM Publishing, 2015. ISBN 978-80-260-8637-6

[MITCalc 2003-2013] MITCalc ${ }^{\circledR}$, MITCalc 1.7, Available from: www. MITCalc.com/en/products.htm, 2003-2013.

\section{Contacts}

Ing. Petr Bernardin, Ph.D.

doc. Ing. Vaclava Lasova, Ph.D.

Ing. Frantisek Sedlacek

University of West Bohemia

RTI - Regional Technological Institute

Univerzitni 22, 30614 Pilsen, Czech Republic

tel.: +42037763 8263,e-mail: berny@kks.zcu.cz

tel.: +42037763 8272,e-mail: lasova@kks.zcu.cz

tel.: +42037763 8272,e-mail: fsedlace@kks.zcu.cz 